Sir,

\section{Posterior polar cataract surgery: a posterior segment approach}

We read with interest the article 'Posterior polar cataract surgery-A posterior segment approach' by Ghosh et al. ${ }^{1}$ We would like to highlight certain points that have not been addressed in the paper.

First, all the patients operated upon by the posterior approach will undergo sulcus fixation of intraocular lens, with its inherent side effects as opposed to the anterior approach in which even in the worst of situations more than $50 \%$ of the cases can undergo in the bag implantation of intraocular lens.

Second, the patients in this study underwent implantation of 'silicon' intraocular lens in the sulcus with open posterior capsule. As these patients are also at a higher risk of retinal detachment, subsequent reattachment surgery requiring silicon oil might be challenging. ${ }^{2,3}$

Finally, the authors state that in young patients the posterior hyaloid was not peeled. These cases are predisposed to having an epiretinal membrane later, but no mention has been made of that aspect.

\section{References}

1 Ghosh YK, Kirkby GR. Posterior polar cataract surgery-a posterior segment approach. Eye 2008; 22(6): 844-848.

2 Apple DJ, Federman JL, Krolicki TJ, Sims JC, Kent DG, Hamburger HA et al. Irreversible silicone oil adhesion to silicone intraocular lenses. A clinicopathologic analysis. Ophthalmology 1996; 103: 1555-1561.

3 Eaton AM, Jaffe GJ, McCuen II BW, Mincey GJ. Condensation on the posterior surface of silicone intraocular lenses during fluid-air exchange. Ophthalmology 1995; 102: 733-736.

V Kumar, B Ghosh, U Kaul, M Thakar and N Goel

Guru Nanak Eye Centre, Maulana Azad Medical

College, New Delhi, India

E-mail: drvinod_agg@yahoo.com

Eye (2009) 23, 1879; doi:10.1038/eye.2008.347; published online 7 November 2008

\section{Sir}

\section{Reply to Kumar et al}

We thank Kumar et al for their interest in our article. In answer to their points: first, the IOL's were all in the sulcus and we appreciate there can be problems from this later. However, to date there have been no complications seen by, or reported to us, in the treatment group.

Second, silicone lenses were used. Most of the patients had a full vitrectomy including peel of the posterior hyaloid and would not therefore be expected to develop retinal detachment (RD) in the future. Even if they did, very few patients require silicone oil in the treatment of $\mathrm{RD}$ - so we consider this of low risk. However, there is no objection to the use of an acrylic lens in this operation if preferred by the surgeon.

Finally, in our experience, failing to remove the posterior hyaloid in the few young patients has not resulted in epiretinal membrane formation. In fact the main risk in this group would be RD later when the posterior hyaloid finally spontaneously separates.

Y Ghosh and GR Kirkby

Department of Ophthalmology, Birmingham \&

Midland Eye Center, Birmingham, UK

E-mail: yajati_ghosh@hotmail.com

Eye (2009) 23, 1879; doi:10.1038/eye.2008.344; published online 21 November 2008

\section{Sir, \\ Ophthalmia neonatorum: a vanishing disease or underreported notification?}

Ophthalmia neonatorum is conjunctival infection within the first 28 days of life and is commonly used to refer to those cases caused by Neisseria gonorrhoeae or Chlamydia trachomatis. Ophthalmia neonatorum is a notifiable

disease in England and Wales. The public health actions that should follow notification are designed to reduce the morbidity associated with ophthalmia neonatorum and prevent further spread of infection. Statutory notifications have reduced markedly over the past decade (Table 1$){ }^{1}$

In Leeds (West Yorkshire, UK) the number of notifications to the Local Authority has also been in decline (Figure 1$)^{2}$

\section{Case report}

To address the question of compliance with notification we compared the number of cases notified with the number of eye swabs positive for $N$. gonorrhoeae or C. trachomatis in children $\leqslant 28$ days between January 2006 and March 2008.

The number of eye swabs submitted in each year were 153,123 , and 38 respectively.

Table 2 shows the number of positive laboratory findings and cases reported to the HPA. This confirms that there is underreporting of ophthalmia neonatorum in Leeds.

There are four possible explanations for the decline in notification of cases of ophthalmia neonatorum: (i) the incidence of neonatal conjunctivitis is falling; (ii) there is failure to notify positive cases; (iii) possible cases are not being sampled adequately; or (iv) the detection methods used in the laboratory are inadequate.

Table 1 Number of reported cases of ophthalmia neonatorum in England and Wales by year (1998-2006)

\begin{tabular}{cccccccccc} 
Year & 1998 & 1999 & 2000 & 2001 & 2002 & 2003 & 2004 & 2005 & 2006 \\
\hline Cases & 198 & 163 & 176 & 115 & 91 & 102 & 85 & 87 & 100
\end{tabular}




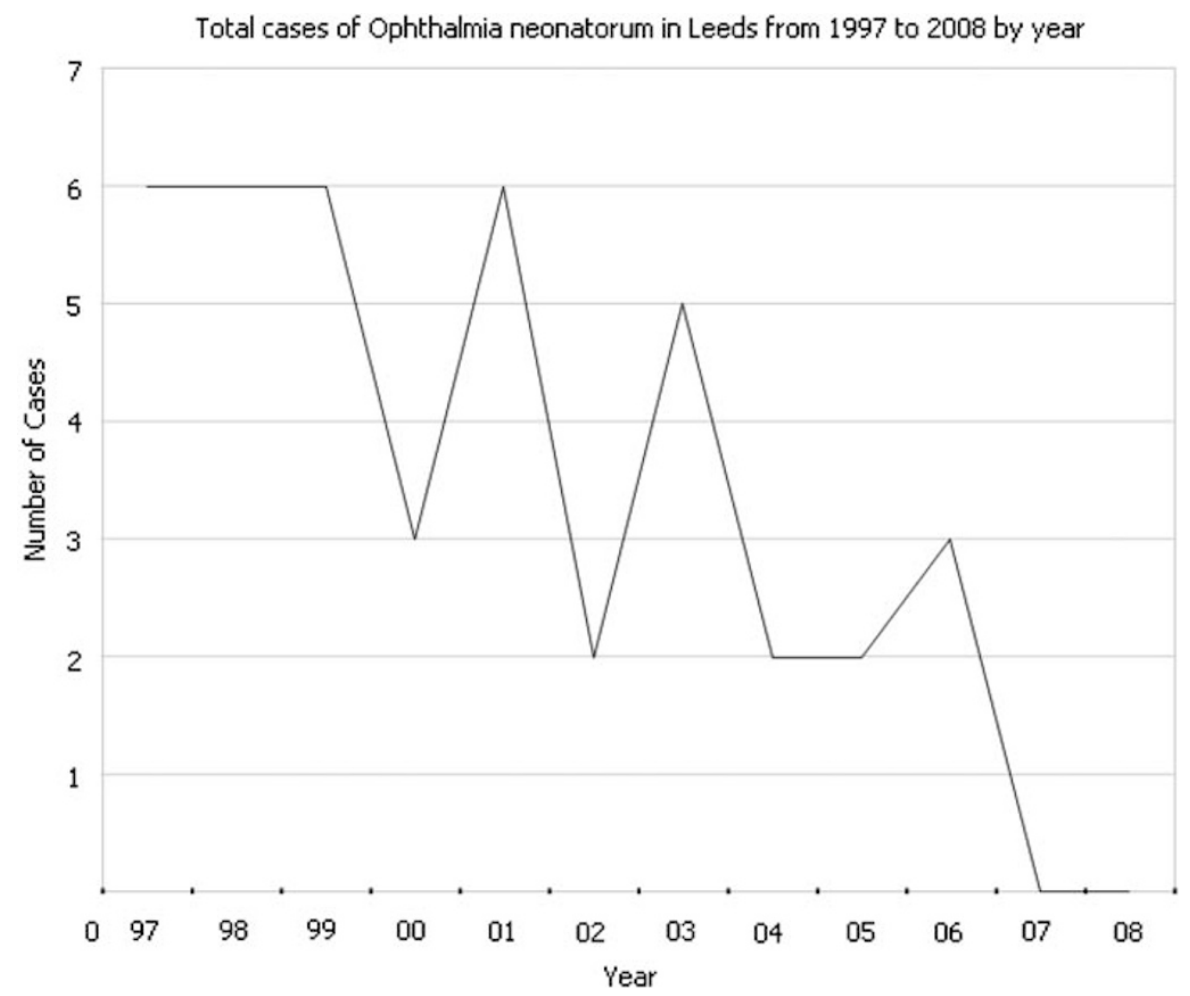

Figure 1 Total cases of ophthalmia neonatorum in Leeds from 1997 to 2008 by year.

Table 2 Number of positive laboratory samples and cases reported/unreported (2006-2008)

\begin{tabular}{lccc}
\hline Year & 2006 & 2007 & 2008 \\
\hline N. gonorrhoeae & 0 & 0 & 0 \\
C. trachomatis & 6 & 5 & 3 \\
HPA reports & 3 & 0 & 0 \\
Cases not reported & 3 & 5 & 3 \\
\hline
\end{tabular}

\section{Comment}

We have shown that there is under notification of ophthalmia neonatorum. It is the responsibility of the referring clinician to report cases of suspected ophthalmia neonatorum, which should be done on clinical grounds, with the laboratory test used as a welcome confirmation of the diagnosis. To improve reporting rates all positive swab reports have had an 'autocomment' added reminding the clinician of their duty to report the case to the HPA. Underreporting of ophthalmia neonatorum has implications for national monitoring and for limiting the morbidity of the condition for patients, mothers, and the community at large. We would welcome similar studies on a national basis to determine how widespread a problem this may be.

\section{References}

1 HPA. Statutory notifications of infectious diseases: annual totals 1994-2006: England and Wales. 2007. http:/ / www.hpa.org.uk/webw/HPAweb\&HPAwebStandard/ HPAweb_C/1195733756346?p = 1191942172956 .

2 HPA Leeds. Total number of reported cases of ophthalmia neonatorum in Leeds 1997-2008.

R Pilling1, V Long ${ }^{1}$, R Hobson ${ }^{2}$ and M Schweiger ${ }^{3}$ ${ }^{1}$ Department of Ophthalmology, Leeds Teaching Hospitals, Leeds, West Yorkshire, UK ${ }^{2}$ Department of Microbiology, University of Leeds and Leeds Teaching Hospitals NHS Trust, Leeds, West Yorkshire, UK

${ }^{3}$ Center for Communicable Disease Control, West Yorkshire Health Protection Unit, HPA Laboratory, Bridle Path, Leeds, UK

E-mail: rfpilling@btopenworld.com

Competing Interests: None declared. Funding: none.

Eye (2009) 23, 1879-1880; doi:10.1038/eye.2008.364; published online 12 December 2008

Sir, Reversed vaulted AcrySof intraocular lens presenting as pupillary block

We report a case of a patient who 4 weeks after uneventful phacoemulsification, underwent a dilated fundal examination, and subsequently developed pupil block. The intraocular lens was noted to be reversed, and thereby vaulted anteriorly. Repositioning of the lens into 